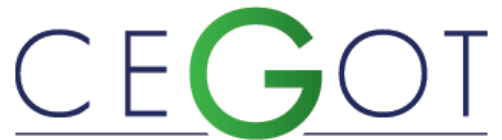

Centro de Estudos de Geografia e Ordenamento do Território

Geografia e Ordenamento do Território, Revista Eletrónica Centro de Estudos de Geografia e Ordenamento do Território http://cegot.org

SMANIOTTO, CARLOS

Universidade Lusófona de Humanidades e Tecnologias, CeiED

- Centro de Estudos Interdisciplinares em Educação e

Desenvolvimento

Campo Grande 376, 1749-024, Lisboa, Portugal

smaniotto.costa@ulusofona.pt

ALMEIDA, INÊS

Universidade Lusófona de Humanidades e Tecnologias, CeiED

- Centro de Estudos Interdisciplinares em Educação e

Desenvolvimento

Campo Grande 376, 1749-024, Lisboa, Portugal

ines.almeida@ulusofona.pt

BATISTA, JOANA

Universidade Lusófona de Humanidades e Tecnologias, CeiED

- Centro de Estudos Interdisciplinares em Educação e

Desenvolvimento

Campo Grande 376, 1749-024, Lisboa, Portugal

joana.batista@ulusofona.pt

Menezes, MARLUCI

Laboratório Nacional de Engenharia Civil - LNEC

Av. do Brasil, n. 101, 1700-066, Lisboa, Portugal

marluci@Inec.pt

\title{
Envolver adolescentes no pensar a cidade: reflexão sobre oficinas temáticas de urbanismo no Bairro de Alvalade, Lisboa
}

Engaging teenagers in placemaking: reflections on thematic workshops in urban planning in Lisbon's Alvalade Neighbourhood

Referência: Smaniotto, Carlos et. al (2018). Envolver adolescentes no pensar a cidade: reflexão sobre oficinas temáticas de urbanismo no Bairro de Alvalade, Lisboa. Revista de Geografia e Ordenamento do Território (GOT), n. ${ }^{\circ} 15$ (dezembro). Centro de Estudos de Geografia e Ordenamento do Território, p. 117-142, dx.doi.org/10.17127/got/2018.15.006

\section{RESUMO}

O presente artigo, alicerçado nos Projetos de investigação CyberParks e C3Places, examina como as tecnologias digitais podem envolver os utilizadores na cocriação de um espaço público aberto que responda às suas necessidades, explorando o papel mediador das Tecnologias da Informação e da Comunicação (TIC) nesse processo. Partindo de resultados preliminares dos dois projetos, será explorado mais especificamente o uso do espaço público por adolescentes e discutida a necessidade de repensar o espaço público através de uma perspetiva mais participada.

Palavras-chave: Adolescentes, Cocriação, Espaço Público Aberto, TIC.

\section{ABSTRACT}

The present contribution, based on the Projects Cyberparks and C3Places, addresses the question of how digital technologies can be the mediator to engage users towards co- 
creating public open spaces. Aiming at meeting users' needs, both projects explore the facilitating role of Information and Communication Technologies (ICT) in that process. In the light of preliminary findings, this contribution explores teenagers' use of public open spaces and discusses the need to rethink public space through a more participative perspective.

Keywords: Teenagers, Co-creation, Public Open Space, ICT.

\section{Introdução}

A presente contribuição é baseada na discussão de resultados emergentes de dois projetos europeus de investigação - CyberParks (COST Action TU1306, www.cyberparks-project.eu e C3Places (Horizonte 2020/JPI UrbanEurope, www.c3places.eu). Estes dois projetos partilham o objetivo geral de melhor compreender as características de uso de espaços públicos abertos, explorando para esse efeito o potencial mediador das Tecnologias da Informação e da Comunicação (TIC). Ambos combinam contributos de áreas específicas do conhecimento como o planeamento e urbanismo, a antropologia e a informática. A inter/multidisciplinariedade é assumida como perspetiva que contribui para articular diferentes níveis de análise, orientando a definição da metodologia a ser empregue numa investigação sobre espaços públicos abertos para, por um lado compreender as caraterísticas físicas, técnicas e tecnológicas que tornam esses espaços atrativos e, por outro produzir conhecimento acerca das perceções, representações, necessidades e usos dos seus utilizadores.

Numa perspetiva de rede, o Projeto CyberParks (maio de 2014 - abril de 2018) reuniu 88 investigadores e especialistas europeus de diferentes áreas disciplinares para trabalharem em conjunto em torno da interseção entre tecnologia digital, espaços públicos e pessoas. $O$ Projeto C3Places (maio 2017 - abril 2020) pretende explorar o potencial das TIC e de metodologias de cocriação na produção de espaços públicos abertos mais atrativos, inclusivos e que melhor respondam às necessidades e preferências dos utilizadores.

Este artigo apresenta resultados preliminares de um inquérito por questionário e por entrevista, respetivamente realizados a adolescentes estudantes e a jovens profissionais no âmbito do Projeto CyberParks. Em segundo lugar, descreve e discute a operacionalização e o desenvolvimento de uma fase exploratória de cocriação com adolescentes, materializada em quatro oficinas temáticas de urbanismo, desenvolvida pelo Projeto C3Places. Visa-se 
essencialmente apontar determinados aspetos de âmbito teórico que ressaltam da relação entre pessoas (adolescentes) - tecnologia digital - e espaço público.

O espaço público está permanentemente a transformar-se em resposta à sociedade e suas prioridades, também mutáveis. Sabendo-se que o envolvimento das pessoas em processos participativos é dificultado por diversos fatores - e mais ainda no caso particular dos adolescentes - pretende-se explorar ferramentas e mecanismos que possam contribuir para potenciar a criação de espaços públicos atrativos.

\section{O espaço público urbano como palco da interação social}

Por espaço público considera-se o espaço que é de uso e propriedade pública, cujo acesso é gratuito e não visa a obtenção de lucro, sendo criado para proveito de todas as pessoas. Os espaços públicos podem ser abertos, como ruas, passeios, jardins, parques, praças, praias públicas, frentes ribeirinhas; ou fechados, como museus, bibliotecas, complexos desportivos públicos (Biennial of Public Space, 2013). O foco de investigação em ambos os projetos é o espaço público aberto. Doravante, ao longo do artigo, usa-se somente a expressão espaço público como referência a espaço público aberto.

Os espaços públicos são indubitavelmente elementos fundamentais para a prosperidade das cidades, ao facilitarem o capital social e económico, e como parte da paisagem cultural das cidades influenciam decisivamente a qualidade de vida urbana. Os espaços públicos contribuem assim para o desenvolvimento de um sentido cívico e de bem comum. Podem, portanto, constituir-se como uma das plataformas sociais de capacitação cívica e acesso às esferas institucionais e políticas. Enquanto espaço público que é vivido e usado como bem comum poderá fomentar um ambiente urbano saudável e seguro, logo mais atrativo para quem experiencia a cidade (Carmona, 2015; Thompson, 2002; UN Habitat, 2015). Embora os benefícios potenciais sejam reconhecidos, - a possibilidade de o espaço público acrescentar valor (cultural, social, económico), de contribuir para a promoção de um desenvolvimento urbano sustentável e de propiciar uma melhoria na qualidade de vida dos cidadãos - a sua 
importância é por vezes negligenciada pelos decisores políticos, pelos técnicos e mesmo pela produção científica (UN Habitat, 2015; Carmona, 2015; Thompson 2002).

A rede de espaços públicos desempenha um papel essencial na qualidade e proteção ambiental, bem como na oferta de equipamentos verdes que servem para o lazer e a recreação (Smaniotto, Šuklje-Erjavec \& Mathey 2008). Podem nomeadamente desempenhar um importante papel na promoção da atividade física, com benefícios para a saúde física e psicológica da população (Lee \& Maheswaran, 2010; Gascon et al., 2015).

Os espaços públicos partilhados por diferentes pessoas criam oportunidades para ver e ser visto, podendo ser o ponto de partida para as pessoas estabelecerem relações e interações futuras (Gehl, 1987). Estes espaços, podem ser palco para o reconhecimento social e a interação entre cidadãos e para o desenvolvimento de laços sociais. Um espaço público acessível, seguro e convidativo atrai pessoas que, assim, podem estar mais disponíveis para estabelecer contatos sociais (Godbey, 2009; Gehl 1987). É neste cenário que, numa perspetiva de fazer a cidade para as pessoas, o espaço público se apresenta como contexto facilitador de uma aprendizagem vocacionada para o respeito mútuo, onde pessoas de diferentes origens podem envolver-se em atividades comuns, observarem-se, desenvolverem relações e aprenderem um pouco mais sobre os seus diferentes modos de vida (Cattell, Dines, Gesler, \& Curtis, 2008; Klichowski et al. 2015).

O espaço público oferece um ambiente possível e até privilegiado para observar dimensões diversas do fenómeno de socialização, bem como as diferentes e efémeras interações sociais do dia-a-dia, ou as interações que resultam de relações duradouras e identidades partilhadas (Bauman, 2005; Grafmeyer, 1994). Como local de contestação, o espaço público constitui-se ainda como ferramenta para que diferentes grupos sociais reclamem o seu direito ao espaço e validem o seu direito de pertença à sociedade (Mitchell, 1995) ou mesmo à cidade. Com características e histórias próprias, espaços públicos são percecionados de modo diferente e usados de formas díspares por diferentes utilizadores. As práticas sócio-espaciais devem, assim, ser objeto de reflexão, nomeadamente para que melhor se entenda como indivíduos e grupos se apropriam e se vinculam aos espaços específicos. É deste olhar atento sobre a relação recíproca das pessoas com o espaço que devem emergir propostas de intervenção que os transformem em espaços dotados de condições facilitadoras da interação social, de um sentido de comunidade e de bem-estar, 
considerando aspetos tão diversos como o desenho, as atividades oferecidas e desejadas, o tipo de gestão ou as características do utilizador. Para fomentar o desenvolvimento sustentável de áreas urbanas deverão considerar-se estes aspetos, que podem ser enriquecidos através de estratégias de coinvestigação e cocriação que resultem em ferramentas de desenho e em políticas urbanas que contribuam na produção de espaços públicos mais sensíveis aos seus utilizadores.

Os argumentos aqui discutidos, apesar das limitações e das diferentes perspetivas expostas, globalmente preconizam que os espaços públicos abrem uma miríade de possibilidades para a sustentabilidade e prosperidade das cidades.

\section{Os adolescentes como atores de transformação do espaço público}

Envolver as pessoas na cocriação de espaços públicos pode revelar-se uma tarefa complexa, mais ainda se o foco forem os adolescentes. O seu envolvimento em cocriação e a participação social são dificultados pelo facto de os adolescentes serem vistos, muitas vezes, como vulneráveis e dependentes dos adultos, que decidem pelo seu interesse. Acrescentase ainda a ideia de que os direitos devem ser apenas concedidos quando se assume a responsabilidade que deles advém e, no caso dos adolescentes, que a atribuição de responsabilidade pode desvirtuar o direito a uma infância e juventude livres de preocupações (Valentine, 2004).

Os adolescentes experienciam diversas mudanças ao nível do corpo, que se transforma, bem como ao nível da exposição a diversos desafios e experiências que abrem a possibilidade para agirem e movimentarem-se com crescentes graus de liberdade (Breviglieri, 2007; cf. Pappámikail, 2011). No espaço público e em particular nas ruas, os adolescentes encontram um campo privilegiado para interações livres da supervisão dos adultos, o que contribui para moldar as suas identidades (Valentine, 2004). Contudo, várias restrições e imposições ao uso do espaço público condicionam a presença e usufruto destes espaços pelos adolescentes (Laughlin \& Johnson, 2011). Torna-se, então, de considerável 
importância compreender as suas práticas sócio-espaciais, bem como as preferências e necessidades relativas ao uso da cidade, com o intuito de desenhar estratégias que se traduzam em novas políticas públicas urbanas e na concretização de novos projetos.

Para tal, é necessário aprofundar o conhecimento sobre as diferentes características do espaço público, como acessibilidade e qualidade, na perspetiva dos próprios adolescentes, considerando que estes espaços são partilhados e que a sua utilização em simultâneo por diferentes utilizadores deve ser ponderada e negociada. O não reconhecimento e validação da capacidade de participação dos adolescentes também ecoa junto dos técnicos que intervém no espaço em duas principais situações. Uma delas causada pelos técnicos assumirem, frequentemente, não conhecer as necessidades e usos que os jovens têm e fazem do espaço público. Uma outra, refere-se à admissão de inaptidão para envolver os adolescentes no processo de pensar e fazer a cidade, sendo argumentado que os adolescentes não terão ainda os atributos necessários, como responsabilidade, experiência e competência, interesse, legitimidade e poder para participar (White, 2001; Laughlin \& Johnson, 2011; Passon, Levi \& del Rio, 2008). Faltam experiências e um compromisso dos profissionais em envolver e capacitar os jovens no processo participado de pensar a cidade. Mas os desafios surgem ainda noutros domínios, como nas questões temporais associadas aos processos de planeamento e construção, que implicam desenhar planos para o futuro. $\mathrm{E}$, desde o momento do plano à fase de implementação, é inevitável que decorra um grande intervalo de tempo e, estando os adolescentes mais focados no aqui e no agora, têm maior dificuldade em perceber o benefício do seu envolvimento (Valentine, 2004).

Por outro lado, e apesar da inócua e inofensiva intenção dos adolescentes, o seu comportamento nem sempre é bem visto pelos adultos, sendo por vezes avaliado como assustador e ameaçador. Esta reprovação de comportamento pode ser contestada, e uma forma de o fazer será através da criação de espaços públicos que respondam às suas necessidades e aspirações e dos quais não sejam excluídos, quer seja como resultado da discriminação baseada na idade, nos recursos financeiros (como resultado da comodificação dos espaços de lazer) ou ao desinvestimento político nos espaços e equipamentos públicos para esta faixa etária da população (Valentine, 2004).

A falta de espaços adequados às suas necessidades e livres de interferências dos adultos são aspetos reconhecidos pelos próprios adolescentes. A este respeito, Lieberg (1995) indica 
dois tipos de "territórios" no espaço público: os de interação e os de recolhimento. No primeiro há o confronto dos adolescentes com o mundo dos adultos, emergente quando se verifica a partilha de um espaço orientado para adultos (relativamente aos equipamentos e utilizadores) (Valentine, 2004). No segundo, os adolescentes retiram-se para um espaço partilhado com outros adolescentes e no qual os adultos não são bem-vindos. Isso exige um "espaço público tolerante", no qual os adolescentes podem conviver, socializar e realizar diversas atividades recreativas da sua preferência (Passon, Levi \& del Rio, 2008).

O espaço pensado para os adultos não tem que ser aceite como o padrão comum e multiplicável, devendo ser reconhecido que quando este não está preparado para acolher as necessidades dos jovens, pode contribuir para gerar comportamentos que traduzem insatisfação e sentimento de não pertença a esse espaço, e não propriamente um comportamento de transgressão (Malone, 2002; Owens, 2002; Valentine, 2004). Convém, pois, ser considerada uma forma alternativa de produzir as relações sócio-espaciais, uma que permita desenvolver e implementar estratégias de participação cívica. E é fulcral que sejam mais eficazes em termos do envolvimento dos jovens nos processos de tomada de decisão.

A escassa presença dos adolescentes no espaço público, face aos argumentos apresentados, exige reflexões e respostas a diferentes níveis e em diferentes domínios. O Projeto CyberParks começou por explorar esta questão que teve continuidade de forma mais estruturada e direcionada através do Projeto C3Places. As investigações conduzidas neste sentido, bem como alguns dos resultados obtidos, são seguidamente apresentadas e discutidos.

\section{Omnipresença da tecnologia digital: usos, riscos e}

\section{oportunidades}

As TIC têm-se desenvolvido a um ritmo acelerado. O mesmo ocorre com o volume de investigação, inovação e desenvolvimento técnico e tecnológico que crescem a um ritmo sem precedentes, aumentando a competição e o investimento nestas áreas. Especialmente 
se considerarmos as tecnologias digitais e móveis, essa evolução tem-se materializado num desmultiplicar de dispositivos wearable e smart; num aumento global do acesso à rede; no desenvolvimento da Internet das Coisas (IoT), que alargará os dispositivos conectados; e na incorporação de sistemas informáticos em vários dispositivos. Por outro lado, estas tecnologias têm-se também tornado mais acessíveis e o seu uso mais transversal, contribuindo para o emergir de uma sociedade hiperligada. Como vaticinado por Castells (1996), uma vez que a nova revolução tecnológica tem no seu centro o acesso à informação - informação essa que é parte integrante de todas as interações, atividades e práticas humanas, numa lógica de rede e num sistema crescentemente integrado e flexível -, tem potencial para reconfigurar todos os processos de existência coletiva. Por esse motivo, o potencial das TIC na construção e uso dos espaços é refletido como ponto fundamental de investigação pelos Projetos CyberParks e C3Places. As TIC são vistas tanto pela perspetiva de novas e emergentes formas de apropriação espacial, bem como pela oportunidade que elas abrem como novas ferramentas de participação cívica na construção de espaços mais atrativos.

O debate sobre as vantagens e/ou desvantagens da tecnologia é complexo e é frequentemente apresentado de forma simplista e extremada. Winner (1986) afirma a existência de uma teoria do determinismo social da tecnologia. Neste contexto, a tecnologia é apresentada como manifestação dos sistemas económicos e políticos no seio dos quais ela é produzida; e os produtos tecnológicos como enviesados, pois projetados, desenvolvidos e desenhados em condições específicas e por pessoas de características particulares, retendo no seu próprio desenho qualidades e configurações físicas que podem excluir o seu uso por grupos singulares. Esta situação é particularmente visível nas tecnologias e nos processos usados na arquitetura e no planeamento urbano. Por outro lado, o determinismo tecnológico manifesta-se também em visões extremadas da tecnologia como cura para todos os males da sociedade ou como a sua causa (Winner, 1986).

Contudo, o potencial (ou a falta dele) da tecnologia deve ser procurado na forma como esta é apropriada, olhando para os seus usos, configurações, oportunidades e problemas, e reconhecendo que a tecnologia (digital ou de outro tipo) encontra-se sempre sujeita a processos complexos de produção e a dinâmicas abertas e inesperadas de uso, apropriação e reconfiguração, que podem inclusive pôr em causa ou destruir o motivo da sua criação 
(Greenberg, 2013). O digital, especificamente, emergiu como um processo de grande intensidade e complexidade e de efeitos imprevisíveis, mas entrelaçados nos processos sociais. Por esse motivo, os dispositivos e ferramentas digitais e móveis têm de ser considerados, tanto a nível teórico-conceptual, como prático, pela sua componente relacional (Ruppert, Law \& Savage, 2013): na redefinição das relações interpessoais, entre os indivíduos e seu meio, e entre os cidadãos e o seu governo.

A omnipresença da tecnologia no dia-a-dia dos cidadãos coloca riscos de segurança, privacidade, vigilância, isolamento social, inatividade física, entre outros, que não podem ser desconsiderados em investigações que se debrucem sobre o assunto. Todavia, essa mesma omnipresença abre novas oportunidades. A internet permitiu atribuir às práticas sociais propriedades particulares de rastreamento, agregação e acesso (Venturini, 2012) que facilitam o processo de recolha de informação, disponibilizando mais recursos e ferramentas, maior quantidade de informação e em locais de mais fácil acesso (Duarte \& Mateus, 2017). O digital permitiu também, a um novo nível, o teste, experimentação e produção colaborativa de produtos e conhecimento, numa lógica não comercial, e aumentado a cultura participativa (Jenkins, 2009). Para os profissionais das áreas do planeamento e desenho urbano, o desafio é o de usufruir do potencial colaborativo das tecnologias digitais no envolvimento de outros públicos, sobretudo no que respeita ao planeamento e construção de espaços mais sensíveis às necessidades das pessoas.

O Projeto CyberParks analisou exemplos de como a tecnologia digital pode criar valor social, mas este é somente criado quando as tecnologias digitais forem empregues de forma deliberada no processo de construção do espaço. Este projeto cunhou o termo cyberpark como referência a um tipo de espaço que infere uma presença ubíqua (e em interação) da tecnologia no âmbito da relação entre natureza e sociedade, gerando experiências mediadas do seu uso. As experiências analisadas pelo Projeto CyberParks demonstram que as TIC podem causar e permitir práticas sócio-espaciais inovadoras.

O contributo das TIC vai ainda desde a extração e análise de grande volume de dados, ao suporte (mediado) para o envolvimento das pessoas nos processos públicos, à ajuda no planeamento e desenho dos espaços públicos, ao uso de mobiliário urbano inteligente, como meio de partilha de informação e realidade aumentada. O aspeto de maior relevo prende-se com a capacidade da tecnologia digital para criar interações com (potenciais) 
utilizadores. Esta oportunidade possibilita a transformação dos processos de produção dos espaços públicos de algo estático - iniciado, desenvolvido e operacionalizado por técnicos e profissionais - para algo interativo e, ou potencialmente mais criativo, por envolver um conjunto maior de perspetivas, ou mais adequado por permitir a participação daqueles que irão usar o espaço após a sua construção.

O Projeto C3Places explora, por seu lado, o potencial das ferramentas e dispositivos TIC (apps, chats, redes sociais) no processo de cocriação de espaços públicos, envolvendo vários tipos de utilizadores em sessões de cocriação que captem as suas perceções, representações e usos, assim como as suas necessidades específicas no espaço público. Diferentes utilizadores (jovens, idosos e portadores de deficiência motora) serão as populações alvo de estudo, através da realização de quatro estudos de caso nas seguintes cidades europeias, parceiras do projeto: Gante, Lisboa, Milão e Vilnius.

\section{Um olhar sobre o uso dos espaços públicos e das tecnologias digitais pelos jovens: reflexões do Projeto CyberParks}

Os projetos de investigação aqui mencionados partilham entre si vários pontos: 1) o foco na relação entre pessoas - tecnologias digitais - espaços; 2 ) a exploração do potencial das TIC no planeamento, construção e/ou uso do espaço; e 3) a exploração das práticas dos utilizadores do espaço público. Outro ponto em comum é o da aplicação de métodos de inquirição a vários públicos-alvo de utilizadores do espaço público, de modo a compreender as diferenças / semelhanças entres as perceções e necessidades dos diversos utilizadores, assim como dos profissionais que planeiam, desenham e implementam esses mesmos espaços (Smaniotto Costa \& Šuklje-Erjavec, 2018).

Em Lisboa, o estudo de caso do Projeto C3Places tem como público alvo os adolescentes, pelo que é também de interesse abordar os resultados obtidos pelo Projeto CyberParks relevantes para este grupo etário. Aqui são examinados os resultados de três atividades que abordam as relações entre adolescentes, espaços públicos e utilização das TIC: entrevistas semiestruturadas realizadas a jovens profissionais, questionários aplicados a adolescentes 
em quatro cidades diferentes e um estudo mais aprofundado levado a cabo em Hannover (Alemanha) com um grupo mais alargado de adolescentes. As secções seguintes terão como objetivo a apresentação de alguns resultados recolhidos no âmbito do Projeto CyberParks, referentes às práticas e padrões de comportamento dos adolescentes e que foram considerados pelo Projeto C3Places como pontos exploratórios para a investigação posterior.

\subsection{Visões de jovens profissionais sobre tecnologia e espaços públicos}

No âmbito de uma formação especializada intitulada Co-creating Inclusive \& Mediated Public Spaces, que decorreu em Lisboa em fevereiro de 2017, foram entrevistados - por investigadores do Projeto CyberParks - 17 alunos de mestrado e doutoramento de diversas áreas (arquitetura, arquitetura paisagística, urbanismo, design, sociologia e ciências da computação), provenientes de 10 diferentes países europeus, com idades compreendidas entre os 22 e os 35 anos. Os participantes responderam a duas questões acerca da perceção de transformações causadas pelas TIC, em relação à comunicação e interação social e em relação à reconfiguração e transformação espacial. O objetivo foi melhor conhecer alguns dos pontos de vista de jovens profissionais a especializarem-se em áreas relacionadas com o planeamento urbano e desenvolvimento social.

As entrevistas foram analisadas seguindo o método de análise temática (proposto por Braun \& Clarke, 2006). De relevância nesta análise foi a importância dada por todos os entrevistados à tecnologia no seu dia-a-dia. Os temas emergentes na análise foram:

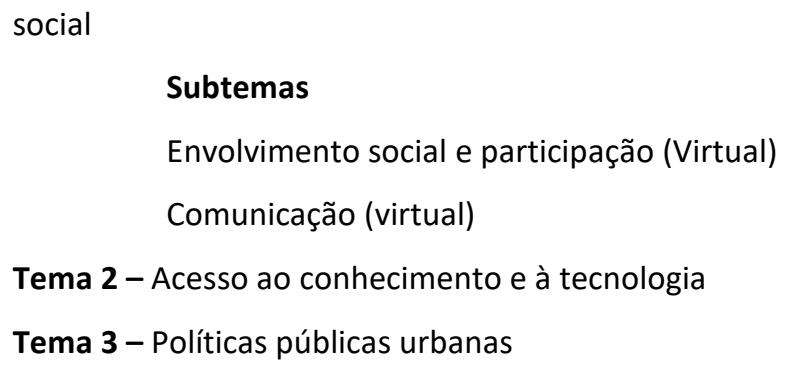

Figura 1. Temas emergentes da análise 
O primeiro tema - Competências interpessoais / Comportamento e interação social descreve as possibilidades para as pessoas participarem facilmente no mundo virtual, o que pode reduzir (ou não) o contato com o espaço físico. O tema foca-se no impacto das TIC nas relações interpessoais e reconhece os benefícios e riscos do seu uso. Os entrevistados revelaram preocupações acerca das transformações nas interações sociais causadas pela omnipresença da tecnologia. Uma opinião comum é a de que os dispositivos móveis estão a adquirir um papel central na comunicação e partilha de informação, mas este facto é mencionado de forma ambivalente: para uns as TIC abrem oportunidades de contacto entre pares; para outros encontram-se associadas a um empobrecimento das relações face-aface, a um potencial isolamento social, e "a um descomprometimento dos indivíduos dos espaços de interação reais" (E1). Para além disso os entrevistados mencionaram também a relevância das TIC nas relações sociais, mencionando o alto nível de flexibilidade, rapidez e oportunidade de estar em constante contacto com familiares e amigos, oferecendo "oportunidades para estar em contacto que não existiam antes" (E2), mas acrescentando que a qualidade das interações não melhora necessariamente por aumentarem em quantidade.

No segundo tema - Acesso ao conhecimento e à tecnologia - é destacada a forte procura de informação e o seu fácil acesso. Para os entrevistados é inegável o volume de informação facilmente acedida que as TIC permitem, contudo, revelaram também preocupações em relação à dependência excessiva da "ligação à tecnologia e dispositivos" (E2). Destacaram também a possibilidade de o seu uso gerar ou intensificar disparidades sociais préexistentes, excluindo os que por razões diversas não têm capacidade e/ou oportunidade de se atualizar ao nível da literacia digital: "Se o desenvolvimento das TIC continuar como até agora poderemos ter grandes lacunas entre diferentes partes da sociedade, causadas pelas TIC" (E3). A possibilidade de a tecnologia digital ser usada para "melhorar o nosso contato com a natureza (...) e criar grandes oportunidades para trazer as pessoas para o exterior" (E12) também foi discutida pelos entrevistados. O uso inapropriado das TIC e a divulgação de dados pessoais, com a perda de privacidade, foi outra dimensão analítica refletida dentro deste tema.

O terceiro tema - Políticas públicas urbanas - inclui questões emergentes das possíveis transformações no uso dos espaços públicos. Uma opinião transversal é a de que estão a 
emergir novos usos dos espaços públicos, mas sem alterações significativas às suas caraterísticas físicas. Dois subtemas identificados foram: 1) a identidade dos espaços públicos, sendo mencionado que a omnipresença da tecnologia a tornará, de forma crescente, parte integrante dos espaços públicos, contudo apenas "transformações menores serão visíveis" (E2). É considerado que os espaços públicos não sofrerão transformação ao mesmo ritmo acelerado que as tecnologias uma vez que "o ciclo de vida da tecnologia é pequeno, não acompanhando o ciclo de vida dos espaços públicos, tanto em termos de desenho, gestão como de questões culturais" (E3); 2) as funções dos espaços públicos, tendo os entrevistados considerado que já existiam usos e funções divergentes dos espaços públicos e apontado para a relevância destes como espaços privilegiados para a participação cívica e para a cocriação, facto percecionado como "oportunidade para nós [jovens profissionais] para coinfluenciar e às vezes, porque não, cocriar e descobrir as atividades bonitas dos parques onde as pessoas (...) se encontram" (E4). Os entrevistados referem ser expectável que algumas das funções tradicionais dos espaços públicos permaneçam inalteráveis, mas também antecipam o desenvolvimento e implementação de novas regras e políticas nestes espaços. O entrevistado 10 defende esta ideia dizendo que "a motivação para que o espaço público exista não vai mudar radicalmente num futuro próximo. Intrinsecamente as pessoas necessitam das mesmas coisas (...). O que irá mudar é a forma como os espaços públicos podem existir (...) serão subtraídos (...) e misturados com os interesses privados".

\subsection{Práticas e usos do espaço e da tecnologia por adolescentes de Hannover, Alemanha}

No seio do Projeto CyberParks foi realizado um pré-inquérito por questionário sobre relações sócio-espaciais junto de adolescentes de quatro cidades - Hannover (Alemanha), Lisboa (Portugal), Tel Aviv (Israel) e Volos (Grécia). Um dos principais objetivos deste pequeno estudo era que o mesmo funcionasse como um pré-teste para melhor definir questões e formas de abordar o público adolescente. Os resultados da análise foram explorados por Menezes, Arvanitidis, Smaniotto Costa \& Weinstein (2018). Adicionalmente em Hannover foram questionados mais 21 adolescentes (entre $15-16$ anos) do 10 ano de escolaridade e em contexto de aula (inserido em atividade da disciplina de Inglês). Resultados de relevo a apontar são a omnipresença dos equipamentos tecnológicos e 
digitais no quotidiano destes jovens: todos os inquiridos possuíam smartphone e acesso a um computador ou tablet familiar; tinham acesso à internet tanto em casa como na escola; todos usavam plataformas digitais ou redes sociais para comunicarem com os pares; e usavam o telemóvel em todas as atividades do dia-a-dia (trocar mensagens, falar com os amigos, partilhar imagens). Em relação aos espaços públicos todos mencionam viver próximo de um espaço público, contudo a utilização dos mesmos varia bastante em frequência: a percentagem mais significativa (39\%) afirma usar um espaço público poucas vezes ao longo da semana, e o motivo mais frequente (33\%) é o de estar com os amigos.

\subsection{CyberParks e C3Places: convergência de experiências}

As perspetivas e opiniões dos jovens profissionais e os resultados do inquérito relativo aos usos da tecnologia digital e dos espaços públicos pelos adolescentes, conforme abordagem metodológica do Projeto CyberParks foram usados como ponto de partida para a exploração temática e definição metodológica da linha de investigação a seguir no estudo de caso de Lisboa, desenvolvido pelo Projeto C3Places e que tem como alvo os adolescentes.

Os resultados obtidos pelo CyberParks apontam para um apreço dos jovens pelas tecnologias móveis e digitais, especialmente no que concerne ao acesso à informação e à comunicação / interação com os pares. Estes resultados vão de encontro ao identificado em outros estudos. Boyd (2014), por exemplo, num estudo etnográfico sobre as práticas digitais de adolescentes norte-americanos, argumenta que, a maioria utiliza a tecnologia para socialização - comunicação com amigos, participação na comunidade, combinar encontros face a face, etc. Práticas que, embora mediadas pela tecnologia, não são necessariamente alteradas pelo uso da mesma. Este aspeto também é válido para as práticas espaciais e de uso dos espaços públicos (tanto pelos adolescentes como outros utilizadores), mesmo quando mediadas pela tecnologia, não são necessariamente alteradas por ela. Esse princípio deverá ser levado em conta na exploração da relação entre tecnologia, espaços públicos e seus utilizadores, o que não deslegitima o reconhecimento, à partida, do potencial das TIC para uma construção mais colaborativa e participada dos espaços públicos. Aplicar esse princípio é reconhecer que as necessidades, valores e ideias dos utilizadores são 
importantes, independentemente de uma mediação na sua experiência espacial, e explorálas deverá ser o primeiro passo de qualquer investigação que pretenda resultar em recomendações para a cocriação de espaços mais atrativos, sensíveis e inclusivos.

Tendo este princípio em mente, o estudo de caso do Projeto C3Places, apesar de ter como um dos objetivos o desenvolvimento de uma app e a experimentação com ferramentas digitais no processo de cocriação dos espaços públicos, baseou-se numa primeira fase "analógica". Esta fase teve como objetivo captar as perceções, necessidades e ideias dos adolescentes para o espaço, e principalmente dotá-los de competências e ferramentas para expressar as suas necessidades no processo de cocriação.

\section{Living Lab em Lisboa: sobre o recurso a metodologias}

\section{colaborativas com adolescentes}

No âmbito do Projeto C3Places, o estudo de caso de Lisboa tem como objetivo último a apresentação de recomendações para a produção de espaços públicos abertos inclusivos e atrativos e, sobretudo sensíveis às necessidades dos adolescentes. Uma abordagem compreensiva (explicitada na figura 2) foi desenvolvida com o propósito de explorar os três elementos do eixo: pessoas - tecnologias - espaços. Central na abordagem foi a operacionalização de oficinas (living labs) temáticas de urbanismo - tomadas como contexto privilegiado à cocriação - com adolescentes-estudantes numa escola secundária no Bairro de Alvalade. A fase exploratória dos living labs decorreu de fevereiro a maio de 2018 e foi desenvolvida tendo por base princípios colaborativos de criação e investigação e metodologias de educação não-formal. Através das oficinas pretendia-se contribuir para a capacitação dos jovens no envolvimento com o espaço que os rodeia a três níveis diferentes: 1) recolha de perceções e exploração conceptual das questões espaciais; 2) apresentação e exploração das oportunidades de participação (em geral e pela mediação tecnológica) e 3) a coprodução de conhecimento respetiva ao planeamento e desenho do espaço público. Os objetivos, metodologias e a descrição das oficinas foram também discutidos em: Almeida, Solipa Batista, Menezes \& Smaniotto Costa (2018). 


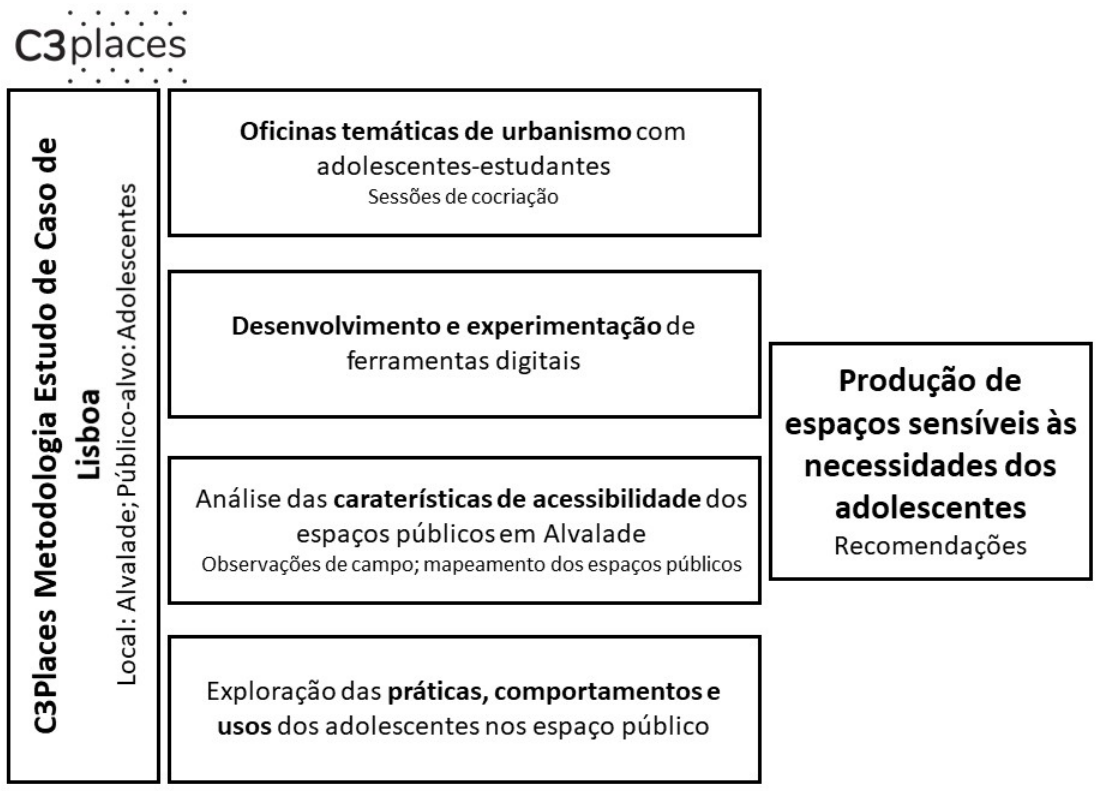

Figura 2. Metodologia estudo de caso de Lisboa.

\subsection{Living labs: o Bairro de Alvalade, os adolescentes e a estrutura das oficinas}

O contexto espacial da investigação é o Bairro de Alvalade, em Lisboa, escolhido por constituir um exemplo distintivo e paradigmático do urbanismo da cidade. A construção do Bairro foi iniciada em 1947, tendo por base o Plano de Urbanização da Zona a Sul da Avenida Alferes Malheiro (1940-45) projetado por João Guilherme Faria da Costa, considerado o primeiro urbanista português. Este plano combinou elementos diferentes, como a cidade tradicional, cidade jardim, Siedlung Alemã e movimentos modernistas - num modelo urbano integrado. O plano dava prioridade à habitação de renda controlada e foi implementado por fases, ao contrário da urbanização caótica registada na expansão de outras freguesias lisboetas. Alvalade foi estruturado a partir de largas vias de circulação e com oito células habitacionais desenvolvidas tendo como núcleo central um equipamento escolar. As áreas residenciais são intercaladas com áreas comerciais, de serviços e edifícios públicos (e. g. mercado), e vários pequenos espaços verdes vicinais. A Mata de Alvalade (Parque José Gomes Ferreira) é a única área arborizada de grande dimensão (11 hectares). Para além disso, os passeios largos, com árvores e bancos, e as praças são comuns, o que 
oferece espaços públicos convenientes e utilizáveis entre os edifícios e as vias de circulação $(\text { Costa, 2002) })^{1}$.

A fase exploratória dos living labs materializou-se em quatro oficinas temáticas de urbanismo, cada uma composta por quatro sessões, num total de 24 horas de intervenção e decorreram no ano letivo de 2017/2018 com alunos do 10 ano na Escola Secundária Padre António Vieira, em Alvalade. As oficinas foram integradas numa disciplina adotada pela escola em resposta à integração da mesma no projeto piloto de Autonomia e Flexibilidade Curricular do Ministério da Educação (Gabinete do Secretário de Estado da Educação, 2017). A integração no currículo escolar permitiu facilitar o acesso, de uma forma ética e responsável, aos adolescentes, e num contexto onde já se encontravam atores a eles familiares (professores) que funcionaram como intermediários no processo de familiarização e interação entre as partes. A integração na carga horária escolar facilitou também o processo por reduzir o esforço necessário pelos adolescentes à participação no projeto.

Os temas dos living labs foram: 1) Um olhar crítico sobre a cidade; 2) A construção da cidade; 3) A era digital e a cidade; e 4) Projetar um espaço público urbano. As sessões foram planeadas para decorrerem em contexto de sala de aula e em espaços públicos no bairro. No desenvolvimento e operacionalização das sessões foram privilegiadas atividades interativas, formais e informais, com recurso a suportes apelativos (figuras 4 e 5) que permitissem aos jovens expressar os seus valores e ideias sem restrições (seguindo as sugestões para educadores e profissionais nas áreas do planeamento urbano e desenvolvimento comunitário apresentadas por Canadian Institute of Planners, 2002). Algumas das atividades desenvolvidas foram: expedições pelo bairro de Alvalade para exploração, observação e registo das características espaciais; atividade de debate entre pares; atividades de discussão das ideias e valores dos adolescentes para o espaço, como por exemplo exercício com post-its e marcadores para registo do "Espaço Público Ideal" (figura 3) para os adolescentes, e a escrita conjunta de uma "Carta Comunitária" onde constavam as questões urbanas de interesse para a sua comunidade. Foi também promovida a partilha de conhecimentos entre os vários atores envolvidos no processo da

\footnotetext{
${ }^{1}$ Importante apontar que o bairro de Alvalade é espacialmente mais limitado do que a Freguesia de Alvalade, cujo território administrativo aumentou consideravelmente após a Reorganização Administrativa de Lisboa em 2012 (Assembleia da República, 2012).
} 
construção da cidade, tendo estado presentes representantes do poder local, da sociedade civil e de uma plataforma de crowdsourcing para discutir estratégias e ferramentas de participação no planeamento urbano. As sessões culminaram numa atividade de desenho em que os adolescentes apresentaram propostas e sugestões de transformações a um espaço público em Alvalade (exemplos na figura 4). Em prol da transparência e do retorno do trabalho aos adolescentes que o cocriaram, os materiais produzidos foram devolvidos à comunidade escolar, através de cartazes expostos no átrio da escola.
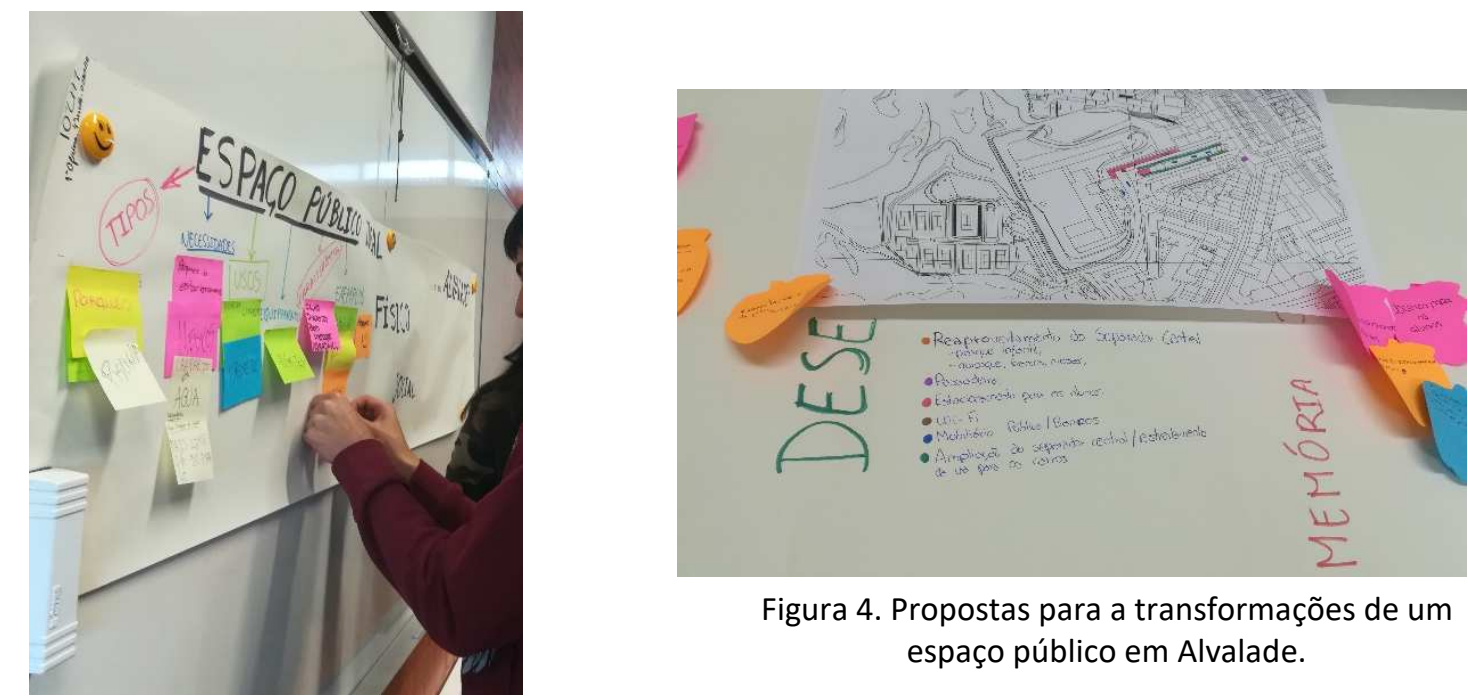

Figura 4. Propostas para a transformações de um espaço público em Alvalade.

Figura 3. Atividade em sala - discussão sobre o espaço ideal para acolher as necessidades dos adolescentes.

\subsection{Resultados preliminares: o contexto, os métodos e as perceções, representações e necessidades espaciais}

A análise dos materiais produzidos nestas sessões ainda está a decorrer, pelo que de momento somente alguns comentários preliminares serão explorados, fruto da observação realizada pelos facilitadores ao longo das oficinas.

Em relação ao contexto da intervenção, apesar dos princípios de cocriação, coinvestigação e das metodologias de educação não-formal empregues, a integração dos living labs no currículo escolar, sendo vantajoso ao bom desenvolvimento dos mesmo pelas razões já apresentadas, condicionou o voluntarismo da participação dos adolescentes, o que tem de ser considerado na análise do material produzido. Os métodos usados foram, de forma geral, bem-recebidos e a participação e envolvimento dos adolescentes foi positiva. Contudo, desde início que ficou clara a necessidade de uma estruturação mais formal das 
atividades e de uma apresentação e descrição mais pormenorizada de linhas orientadoras, procedimentos e possibilidades de resposta para que as atividades fossem compreendidas e realizadas. Foi também possível observar como as caraterísticas individuais influenciam o que é retido e valorizado, reagindo os adolescentes de forma diferente aos mesmos estímulos, alguns mais motivados pelo processo de discussão e pelos métodos não formais propostos, outros pelo conteúdo temático. Observou-se também um apreço geral pela apresentação dos trabalhos e principalmente pelo reconhecimento dos pares, que pode ser indicativo de uma necessidade de se expressarem e serem escutados, e revelando a falta de locais e oportunidades para a satisfazer.

As perceções, representações e necessidades espaciais dos adolescentes não são fáceis de analisar. Ao longo das sessões foi possível observar uma fraca literacia urbana e de representação espacial, tanto numa componente mais conceptual como numa mais pragmática, e mesmo acerca de termos que integram o currículo formal escolar (por exemplo na disciplina de geografia). Os adolescentes possuem também poucas referências de base no uso e na reflexão sobre o espaço público, sendo especialmente difícil a compreensão da diferença entre espaços públicos e espaços privados, e surgindo os últimos mencionados com maior frequência (especialmente espaços privados de cariz comercial).

Revelou-se também difícil incentivar o envolvimento dos adolescentes com os espaços públicos no Bairro de Alvalade. Fator explicativo parece ser a proveniência dos adolescentes envolvidos: apenas 15\% habitam na Freguesia de Alvalade, 75\% são provenientes de outras freguesias, e não só do Concelho de Lisboa (60\%), mas também de outros concelhos da Área Metropolitana (32\%). Outras hipóteses explicativas poderão ser a grande dimensão e recente reorganização da freguesia; a localização periférica da escola, com poucos espaços valorizados pelos adolescentes nas proximidades; a preferência pelo uso de espaços privados fechados ou um conhecimento espacial limitado à circulação entre escola-casa ou escola-transportes públicos. Foi possível também observar uma desmotivação pela consciência da existência de um desfasamento temporal entre a participação e o benefício da mesma, devido aos demorados processos de projeção, construção e transformação dos espaços. 


\section{Reflexões finais}

Nas secções prévias foram apresentados resultados de uma perspetiva de investigação que se debruçou sobre a relação entre adolescentes, espaços públicos e tecnologias de informação e comunicação, tendo por objetivo debater diferentes questões emergentes da interação entre esses três elementos. Dois projetos de investigação - CyberParks e C3Places - foram tidos como base para a exploração, por um lado das perceções concetuais dos adolescentes acerca do espaço público e das práticas, usos e visões dos jovens sobre estes espaços e sobre a tecnologia; e por outro lado, acerca das oportunidades trazidas pelas TIC para o avivar do processo participativo de construção da cidade.

Um primeiro aspeto que surge, e sem dúvida merecedor de reflexão, é se existe ou não um espaço urbano diferenciado que responda às necessidades dos adolescentes, ou seja, se tal espaço é, na verdade, necessário e desejado. A experiência do Projeto C3Places aponta para um conjunto de necessidades de uso do espaço público que são similares às mencionadas por outros grupos de utilizadores. Mas, uma análise mais aprofundada dos resultados da primeira fase dos living labs tem ainda de ser realizada para uma melhor compreensão dos requisitos apontados pelos adolescentes, bem como sobre os usos reais do espaço (e de que tipos de espaço) e as temáticas às quais atribuem maior importância.

O espaço público, é tido como esfera de contestação e debate, lugar da luta política e de protesto (Malone, 2002), e nesse sentido um lugar de participação, democracia e inclusão. Mas, se certos grupos, por suas características tão diversas como as socioeconómicas ou etárias, são excluídos dos espaços públicos, surge necessariamente a questão: podem esses espaços continuar a chamar-se públicos? A investigação e literatura preconizam que os jovens são, em contextos diversos, privados e excluídos de usufruírem de certos espaços (ditos) públicos (Lieberg, 1995; Carmona, Heath, Tiesdell \& Oc, 2003; Owen, 2002; Massey, 1998).

Esta exclusão dos adolescentes do espaço público parece ser observada a vários níveis: de forma implícita o acesso é restrito por falta de adaptação dos espaços às suas necessidades; de forma explícita o uso do espaço é condicionado pelas vontades e imposições dos adultos por eles responsáveis (Malone, 2002; Owens, 2002); e por último, a participação dos mesmos nos processos de construção do espaço público é restringida pela incapacidade dos 
profissionais saberem como os integrar e como recolher o seu contributo. Esta situação é, em parte, explicada pela visão hegemónica dos adultos, ora consumidores, ora produtores. Os adultos estão presentes nas políticas urbanas de forma distinta, possuindo uma competência e poder diferentes para influenciar o desenvolvimento da cidade e dos seus espaços públicos. Considerados qualitativamente mais importantes do que os jovens, que, na relação de poder entre as partes, ficam dependentes da vontade e experiência dos adultos (Qvortrup, 1994).

Sob outra perspetiva, encontramos também fenómenos de substituição de espaços públicos por espaços privados, como centros comerciais e cafés. O que conduz ao aumento dos espaços privados de consumo, a um alargamento de processos de gentrificação (Valentine, 2004), a fenómenos de homogeneização e domesticação do espaço público, ou ao que Sorkin (1992) designou por disneyficação do espaço público.

Ao longo deste artigo apresentaram-se e discutiram-se aspetos relacionados com o uso e comportamento de adolescentes nos espaços públicos, conforme observados em algumas cidades europeias. Apesar de os dados recolhidos em Hannover apontarem os espaços públicos como sendo relevantes no dia-a-dia dos adolescentes, devido à pouca expressão estatística dos dados, é necessário questionarmos até que ponto os espaços públicos permanecem como contextos de referência na socialização e interação dos adolescentes com os pares, e com os outros grupos sociais.

Nas oficinas de urbanismo desenvolvidas, os aspetos da privatização do espaço não foram pensados e contemplados reflexivamente pelos adolescentes. E, embora não exista informação sobre o estatuto socioeconómico das suas famílias de origem, percebeu-se pelos discursos e narrativas que esses espaços privados e de consumo são, de forma transversal, os preferidos pelos adolescentes, onde eles não se sentem excluídos por razão de qualquer ordem. É nestes espaços que gostam de estar e se encontrar com os pares, e reclamam da não existência de mais, quer seja na proximidade da escola ou da sua área de residência. Mas, será este facto um indicador que para os adolescentes o espaço público perdeu importância? Estarão estes espaços de socialização, encontro e performatização / construção de uma identidade social a ser substituídos? E será que essa substituição lhes altera a função ou apenas a transfere para espaços privados, muitas vezes fechados? Estas questões têm de ser consideradas, de forma reflexiva, numa investigação que pretenda 
compreender de que forma o espaço público aberto pode ser reconfigurado para permanecer pertinente e exercer um poder de atratividade para os adolescentes e outros grupos de utilizadores.

Assim, quando se concebe o processo de pensar e fazer a cidade de forma participada, este tem de ser analisado de forma integrada e inclusiva, sendo consideradas todas as questões referentes ao processo, mesmo as que, tal como as apresentadas acima, poderão pôr em causa a sua relevância, e sendo dada oportunidade a todos os grupos de potenciais utilizadores para contribuírem. As questões contextuais a cada grupo terão de ser consideradas. Com as crianças e adolescentes, em soluções desta natureza, um equilíbrio terá de ser encontrado entre o respeito pelas suas vontades e não imposição de uma visão exclusivamente adulta do espaço público, e a permanência de estímulos no espaço que respondam aos aspetos fundamentais da construção individual e social da identidade e no seu saudável desenvolvimento. Estímulos que permitam aos adolescentes renegociar a supervisão dos adultos, conviver, falar, observar, brincar, expressar-se, explorar a sua criatividade e experienciar o mundo à sua volta (Malone, 2002; Valentine, 2004; Strecht, 2011).

É assim necessário encontrar um equilíbrio entre as necessidades dos diferentes grupos de utilizadores do espaço público (adolescentes, idosos, portadores de deficiência) para a construção de um espaço sensível, atrativo e inclusivo, não de vários espaços direcionados a um único público alvo, pois isso cria ou reforça fenómenos de exclusão. A conflitualidade entre os utilizadores do espaço é um fator de exclusão pelo que os espaços de cocriação poderão potencialmente funcionar, não apenas com uma função prática de desenho e planeamento, nem apenas como ferramenta participativa, mas também como contextos onde os vários atores envolvidos possam ativamente procurar visões, valores, e necessidades comuns que medeiem as suas interações futuras na partilha do uso do espaço público. Tal como preconizado por Malone (2002), as necessidades e valores dos diferentes utilizadores devem ser levadas em conta na configuração do espaço público e garantir que (re)adquiram a sua função de produção do espaço e identidade local.

Strecht (2011) relembra que o desenvolvimento cognitivo e emocional das crianças e dos adolescentes depende fortemente dos estímulos exteriores, bem como da interação entre a realidade interna e a realidade experienciada quando em contacto com o que os rodeia 
(espaço físico e interações sociais e interpessoais). Características desejadas são ruas de pouco tráfego, passeios largos, espaços amplos entre edifícios, e existência de espaços verdes na proximidade da zona residencial. $\mathrm{O}$ autor salienta ainda a existência de atributos específicos do desenho do espaço, como o tipo e a disposição de equipamentos, que permitam, por exemplo, o "estar" no espaço com os seus pares, ou a existência de mobiliário playable que permita novos usos / funções do espaço, como importantes na construção de cidades sensíveis aos adolescentes.

A construção participada do espaço é também apenas possível se os diferentes intervenientes no processo de pensar a cidade - decisores políticos, profissionais nas áreas do planeamento urbano e urbanismo, arquitetura e desenho - forem sensíveis às necessidades dos utilizadores e sensibilizados para investirem (tempo e recursos) em novas formas e processos de construção espacial. Por esse motivo, auscultar as opiniões dos profissionais prospetivos, tal como realizado pelo Projeto CyberParks, é de extremo interesse para melhor entender as perspetivas, interesses e visões de todos os atores de relevo.

O eixo pessoa - tecnologias digitais - espaços públicos intersecta-se em vários níveis de análise. Primeiramente, na omnipresença dos dispositivos móveis e digitais no dia-a-dia dos adolescentes, e na sua importância como ferramentas de comunicação e socialização. Esta omnipresença pode ser vista como desvantagem por fomentar isolamento social e inatividade física. Contudo, pode ser também vantajosa para a construção de espaços mais interativos onde a tecnologia possa funcionar como fator de atratividade, propiciando novas formas mediadas de apropriação espacial e novos espaços públicos híbridos, tal como apontados pelos jovens profissionais entrevistados no âmbito do Projeto CyberParks.

Neste artigo discutiram-se alguns dos aspetos que tornam o processo de cocriação de espaços públicos dinâmico e complexo. Essa complexidade parece ser ainda maior quando temos como ponto de referência os adolescentes, atores para os quais o espaço público parece em simultâneo e de forma contraditória, surgir como palco onde interpretam a sua individualidade e a sua persona social, mas onde também a opressão ou hegemonia de outros atores (principais - os adultos) os remete para uma posição secundária, por vezes sendo excluídos desse palco de importância social. A peça da cocriação e produção do espaço é uma que se desenvolve em vários atos desfasados temporalmente. Os 
adolescentes, disso tendo consciência, sofrem de uma desmotivação para participar no processo, pois sabem que quando os seus contributos se materializarem já a peça irá no prólogo, a sua adolescência no fim e as suas falas anacrónicas. Por esse motivo, acreditar no potencial de integrar os adolescentes na cocriação do espaço público, e o recorrer a ferramentas digitais (volúveis e em permanente alteração) no processo, é reconhecer que o pensar e construir o espaço urbano é sempre um processo contingente, dinâmico e imprevisível.

\section{Agradecimentos}

Este artigo foi realizado com o apoio da COST Action TU1306 CyberParks (www.cyberparksproject.eu) e do C3Places - Using ICT for Co-creation of Inclusive Public Places (www.c3places.eu), Programa Europeu Horizonte 2020 Programa de Investigação e Inovação (Grant Agreement no. 693443), bem como financiado por fundos nacionais através da FCT - Fundação para a Ciência e a Tecnologia, I.P.

\section{Referências bibliográficas}

ALMEIDA, Inês, BATISTA, Joana S., MENEZES, Marluci, SMANIOTTO COSTA, Carlos. Adolescentes e Cocriação do Espaço Público. Oficinas Temáticas de Urbanismo 2017 - 2018. Relatório Preliminar sobre o Estudo de Caso de Lisboa. 1ạ ed. Lisboa: Edições Universitárias Lusófonas. 2018. ISBN: 978-989757078-0.

ASSEMBLEIA DA REPÚBLICA. Lei n. ${ }^{\circ}$ 56/2012.. Diário da República n. ${ }^{\circ}$ 216/2012, Série I de 2012-11-08. [consultado a 27/07/2018]. Disponível em: http://data.dre.pt/eli/lei/56/2012/11/08/p/dre/pt/html

BAUMAN, Zygmunt. Confiança e Medo na Cidade. 1ạ ed. Lisboa: Relógio d’Água. 2006. ISBN: 9789727088935

BOYD, Dnah. It's Complicated: The Social Lives of Networked Teens. 1a ed. Yale: Yale University Press. 2014 ISBN: 9780300199000. DOI: 10.1007/s10615-014-0512-3

BRAUN, Virginia, e CLARKE, Victoria. Using thematic analysis in psychology. Qualitative Research in Psychology. 2006. ISSN: 14780887. DOI: 10.1191/1478088706qp063oa

CANADIAN INSTITUTE OF PLANNERS. Great Communities : A Manual for Planners and Educators [online\}. The Canadian Institute of Planners. 2002. [consultado a 28/07/2018]. Disponível em: $\underline{\text { www.cip- }}$ icu.ca/Files/Resources/kidsguide.aspx

CARMONA, Matthew. Re-Theorising Contemporary Public Space: A New Narrative and a New Normative. Journal of Urbanism: International Research on Placemaking and Urban Sustainability 8 (4). 2015. 373405.ISSN: 17549183. DOI: 10.1080/17549175.2014.909518 
CARMONA, Matthew, HEATH, Tim, TIESDELL, Steve e OC, Taner. Public Places, Urban Spaces: The Dimensions of Urban Design. 1a ed. Michigan: Architectural Press. 2003. ISBN: 07506 36327. DOI: 10.1111/febs.12167

CASTELLS, Manuel. The Rise of the Network Society, Volume 1 of the Information Age: Economy, Society and Culture. 1a ed. Massachusstts: Blackwell Publishing. 1996. ISBN: 9781405196864. DOI: 10.2307/1252090,

CATTELL, Vicky, DINES, Nick, GESLER, Wil and CURTIS, Sarah. Mingling, observing, and lingering: Everyday public spaces and their implications for well-being and social relations. Health and Place.. Vol. 14, no. 3, p.544561. 2008. ISSN: 13538292. DOI: 10.1016/j.healthplace.2007.10.007.

COSTA, João. P. Bairro de Alvalade: Um Paradigma no Urbanismo Português. 1ạed. Lisboa: Horizonte Arquitectura. 2002. ISBN: 9722413824

DUARTE, Tiago.; MATEUS, Diogo. The Contribution of ICT in Planning of Public Open Spaces - Reflections on the City of Lisbon. Reflections on the City of Lisbon. In: Antoine Zammit and Therese Kenna (Eds.). Enhancing Places through Technology. Proceedings from the ICiTy conference. Valletta, Malta 18-19 April, 2016 (pp. 41 56). Lisboa: Edições Universitárias Lusófonas. 2017. ISBN: 978-989-757-055-1

GABINETE DO SECRETÁRIO DE ESTADO DA EDUCAÇÃO SECRETARIA-GERAL. Despacho n. 5907/2017. Diário da República n. ${ }^{\circ}$ 128/2017, Série II de 2017-07-05. [consultado a 28/07/2018]. Disponível em: https://dre.pt/web/guest/home/-

/dre/107636120/details/2/maximized?serie=II\&parte_filter=31\&dreld=107636088

GASCON, Mireia, MAS, Margarita Triguero, MARTíNEZ, David, DADVAND, Payam, FORNS, Joan, PLASĖNCIA, Antoni and NIEUWENHUIJSEN, Mrk J., Mental health benefits of long-term exposure to residential green and blue spaces: A systematic review. International Journal of Environmental Research and Public Health.. Vol. 12, no. 4. 2015. 4354-4379. ISSN: 16604601. DOI: 10.3390/ijerph120404354

GEHL, Jan. Live between buildings: Using Public Space. 1aed. Nova lorque: Van Nostrand Reinhold. 1987. ISBN: 978-1597268271

GODBEY, Geoffrey. Outdoor Recreation, Health, and Wellness: Understanding and Enhancing the Relationship. Recreation, no. May 2009. 1-42. ISSN: 1556-5068. DOI: 10.2139/ssrn.1408694

GRAFMEYER, Yves. Sociologia Urbana. 1a ed. Mem-Martins: Publicações Europa-América. 1994. ISBN: 9789721040137

GREENBERG, Andy. This Machine Kills Secrets: Julian Assange, the Cypherpunks, and Their Fight to Empower Whistleblowers. 1e.ed. New York: A Plume Book, Penguin Group. 2013. ISBN: 9780142180495

INU, 2013. Charter of Public Space. Biennale Spazio Pubblico [online]. 2013. Available from: www.inu.it/wpcontent/uploads/Inglese charter of public space.pdf

JENKINS, Henry. Confronting the Challenges of Participatory Culture : Media Education for the 21 Century. Program. 2009. ISSN: 07491581. DOI: 10.1108/eb046280

KLICHOWSKI, Michal, BONANNO, Philip, JASKULSKA, Sylwia, SMANIOTTO COSTA, Carlos, DE LANGE, Michiel, KLAUSER, Francisco R.. CyberParks as a New Context for Smart Education: Theoretical Background, Assumptions, and Pre-service Teachers' Rating. American Journal of Educational Research, vol. 3, no. $12 \mathrm{~A}: 1$ 10. 2015. DOI: 10.12691/education-3-12A-1

LAUGHLIN, Danielle L., e JOHNSON, Laura C.. Defining and Exploring Public Space: Perspectives of Young People from Regent Park, Toronto.Children's Geographies 9 (3-4). Routledge. 2011.ISSN: 14733277. DOI: 10.1080/14733285.2011.590703

LEE, Andrew C. K. and MAHESWARAN, Ravi, The health benefits of urban green spaces: a review of the evidence. Journal of Public Health [online]. 2011. Vol.33, no. 2, p.212-222. DOI: 10.1093/pubmed/fdq068. Available from: https://academic.oup.com/jpubhealth/article-lookup/doi/10.1093/pubmed/fdq068

LIEBERG, Mats. Teenagers and public space. Communication Research, 22(6). 1995. 720-744. ISSN: 15523810. DOI: $10.1177 / 009365095022006008$

MALONE, Karen. Street life: Youth, culture and competing uses of public space. Environment and Urbanization, 14(2). 2002. 157-168. ISSN: 09562478. DOI: 10.1177/095624780201400213 
MENEZES, Marluci, ARVANITIDIS, Paschalis, SMANIOTTO COSTA, Carlos, WEINSTEIN, Zvi. Teenagers' perception of public spaces and their practices in ICTs uses. In I. Smaniotto Costa C, and Suklje-Erjavec (Ed.), CyberParks the interface between people, places and technology - New Approaches and Perspectives Heidelberg: Springer. 2018. Em publicação.

MITCHELL, Don. The End of Public Space? People's Park, Definitions of the Public, and Democracy. Annals of the Association of American Geographers. Vol. 85, no. 1. 1995. 108-133. ISSN: 14678306. DOI: 10.1111/j.14678306.1995.tb01797.x

OWENS, Patsi E. No Teens Allowed: The Exclusion of Adolescents from Public Spaces. Landscape Journal, 21(1). 2002. 156-163. ISSN: 0277-2426. DOI: 10.3368/lj.21.1.156

PAPPÁMIKAIL, Lia, A adolescência enquanto objeto sociológico: notas sobre um resgate. In René Bendit, José Machado Pais, Vitor Sérgio Ferreira (orgs.), Jovens e Rumos. Lisboa, Imprensa de Ciências Sociais. 2011. ISBN: 978-972-671-285-5

PASSON, Camille, LEVI, Daniel, e del Rio, Vicente. Implications of adolescents' perceptions and values for planning and design. Journal of Planning Education and Research, 28(1). 2008. 73-85. ISSN: 0739456X. DOI: $10.1177 / 0739456 \times 08319236$

QVORTRUP, Jens. Childhood matters: social theory, practice and politics. Virginia: Avebury. 1994. ISBN: 9781856288569

RUPPERT, Evelyn, Law, John, e Savage, Mike. Reassembling Social Science Methods: The Challenge of Digital Devices. Theory, Culture \& Society. Volume 30, Issue 4. Maio de 2013. ISSN: 14603616. DOI: $10.1177 / 0263276413484941$

SMANIOTTO COSTA, Carlos e ŠUKLJE-ERJAVEC, Ina. CyberParks - the interface between people, places and technology - New Approaches and Perspectives.. Heidelberg: Springer. 2018. Em publicação

SMANIOTTO COSTA, Carlos, SUKLJE ERJAVEC, Ina e MATHEY, Juliane. Green Spaces - a Key Resources for Urban Sustainability. The GreenKeys Approach for Developing Green Spaces. In Urbani Izziv, Vol. 19, No. 2, Mestne zelene površine / Urban green spaces. 2008. 199-211. [consultado em 28/07/2018]. Livre acesso. Disponível em https://www.jstor.org/stable/24906047.

SORKIN, Michael. Variations on a Theme Park: The New American City and the End of Public Space. 1a ed. Nova lorque: Hill and Wang. 1992. ISBN: 9780374523145

STRECHT, Pedro. Uma Certa Harmonia Notas sobre arquitectura, urbanismo e saúde mental infanto-juvenil. 1a ed. Lisboa: Assírio \& Alvim. 2011. ISBN: 978-972-37-1583-5

THOMPSON, Catharine W.. "Urban Open Space in the 21st Century." Landscape and Urban Planning 60 (2). 2002. 59-72. ISSN: 01692046. DOI: 10.1016/S0169-2046(02)00059-2.

UN-HABITAT. Global Public Space Toolkit: From Global Principles to Local Policies and Practice. Nairobi: United Nations Human Settlements Programme (UN-Habitat). 2015. [consultado em 24/01/2018] Disponível em: www.unhabitat.org.

VALENTINE, Gill. Public space and the culture of childhood. Aldershot: Ashgate. 2004.ISBN:0-7546-4254-2.

VENTURINI, Tommaso.. Building on faults: How to represent controversies with digital methods. Public Understanding of Science. Volume 21, Issue 7. 2012. ISSN: 09636625. DOI: 10.1177/0963662510387558

WINNER, Langdon. Do Artefacts Have Politics? In WINNER, Langdon The Whale and the Reactor. A Search for Limits in an Age of High Technology. Ed. 1989. Chicago e Londres: The University of Chicago Press. 1986. ISBN: 0-226-90211-0

WHITE, Rob. Youth participation in designing public spaces [online]. Youth Studies Australia, 20(1), 18. março 2001. 18-26. [consultado a 28 Disponível em: https://search.informit.com.au/documentSummary;dn=200109148;res=IELAPA ISSN: 1038-2569 